\title{
Erratum to: The tetraheme cytochrome from Shewanella oneidensis MR-1 shows thermodynamic bias for functional specificity of the hemes
}

\author{
Bruno M. Fonseca - Ivo H. Saraiva - Catarina M. Paquete - Claudio M. Soares • \\ Isabel Pacheco • Carlos A. Salgueiro • Ricardo O. Louro
}

Published online: 26 January 2011

(C) SBIC 2011

Erratum to: J Biol Inorg Chem (2009) 14:375-385

DOI 10.1007/s00775-008-0455-7

The original publication did not report the final calculated values in Table 2 . This only has a significant consequence for reported geometry of the axial ligands of heme IV and changes one of the 16 panels of Fig. 1.

The updated versions of Table 2 and Fig. 1 are given below.

Table 2

\begin{tabular}{|c|c|c|c|c|c|c|c|c|}
\hline & \multicolumn{2}{|l|}{ Heme I } & \multicolumn{2}{|l|}{ Heme II } & \multicolumn{2}{|l|}{ Heme III } & \multicolumn{2}{|l|}{ Heme IV } \\
\hline & NMR & X-ray & NMR & X-ray & NMR & X-ray & NMR & X-ray \\
\hline$\theta\left({ }^{\circ}\right)$ & $-13.0(0.4)$ & -10.4 & $-46(2)$ & -72.9 & $-28.3(0.4)$ & -33.8 & $-8.5(0.5)$ & -0.9 \\
\hline$\beta\left({ }^{\circ}\right)$ & 0 & 18.2 & 71 & 65.7 & 0 & 6.3 & 53 & 56.8 \\
\hline$\Delta E(\mathrm{~kJ} / \mathrm{mol})$ & $6.0(0.2)$ & & $1.32(0.05)$ & & $6.3(0.2)$ & & $3.5(0.1)$ & \\
\hline
\end{tabular}

The online version of the original article can be found under doi:10.1007/s00775-008-0455-7.

\footnotetext{
B. M. Fonseca - I. H. Saraiva - C. M. Paquete

C. M. Soares · I. Pacheco · R. O. Louro ( $\square)$

Instituto de Tecnologia Química e Biológica,

Universidade Nova de Lisboa,

Av. da Republica (EAN),

2780-157 Oeiras, Portugal

e-mail: louro@itqb.unl.pt

C. A. Salgueiro

Requimte-CQFB, Departamento de Química,

Faculdade de Ciências e Tecnologia,

Universidade Nova de Lisboa,

Quinta da Torre,

2829-516 Caparica, Portugal
} 
Fig. 1
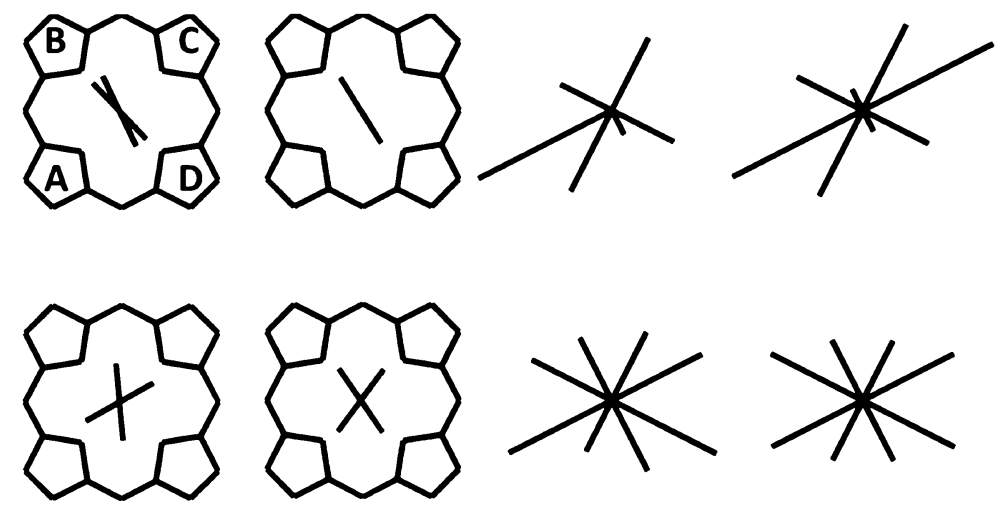

HEME II

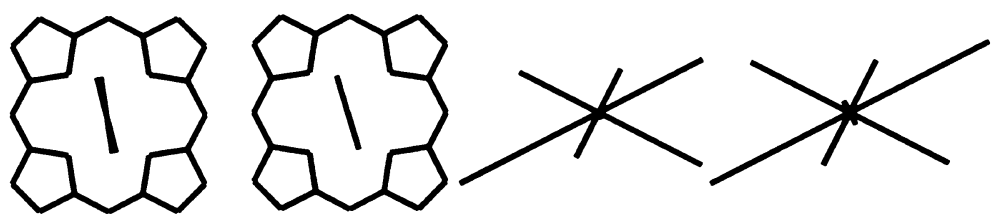

HEME III<smiles></smiles><smiles></smiles><smiles>CC(C)(C)C</smiles><smiles>CC(C)(C)C(C)(C)C</smiles>

HEME IV 